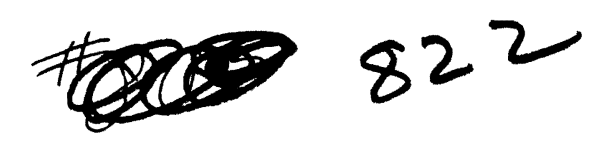

\title{
Changes in Life-Style After Liver Transplantation
}

\author{
Basil J. Zitelli, MD, Joanne W. Miller, PhD, J. Carlton Gartner, Jr, MD, \\ J. Jeffrey Malatack, MD, Andrew H. Urbach, MD, Steven H. Belle, PhD, \\ Laurel Williams, RN, MSN, Beverly Kirkpatrick, MSW, and \\ Thomas E. Starzl, MD, PhD
}

\begin{abstract}
From the Departments of Pediatrics, Psychiatry, Nursing, and Social Services, Children's Hospital of Pittsburgh, Departments of Epidemiology and Surgery, University of Pittsburgh Health Science Center, Pittsburgh
\end{abstract}

\begin{abstract}
Sixty-five pediatric patients who received liver transplants between May 1981 and May 1984 were observed for as many as 5 years and examined for changes in lifestyle. Children were less frequently hospitalized, spent less time hospitalized, required fewer medications, and generally had excellent liver and renal function after hepatic transplantation as compared with their pretransplantation status. Most children were in age-appropriate and standard school classes or were only 1 year behind. Cognitive abilities remained unchanged. Children improved in gross motor function and patients' behavior significantly improved according to parents' perceptions. Enuresis was more prevalent, however, than in the population of children who had not received liver transplants. Parental divorce rates were no greater than those reported for other families with chronically ill children. Overall, objective changes in life-style as well as parents' perceptions of behavior of children appear to be improved after liver transplantation. Pediatrics 1988;82:173-180; liver transplantation, life-style, quality of life.
\end{abstract}

Liver transplantation has been accepted as therapy for children with end stage liver disease largely because of significant improvement in overall survival rates. ${ }^{1}$ As increasing numbers of liver transplantation centers in the United States and in other parts of the world achieve 1-year patient survival rates as great as $82 \%,{ }^{2,3}$ increasing attention has turned to the quality of life after liver transplantation. The potential for improvement in quality of life was a focal point in debates prior to establishing

Received for publication April 8, 1987; accepted June 16, 1987. Reprint requests to (B.J.Z.) Children's Hospital of Pittsburgh, One Children's Place, 3705 Fifth Ave at Desoto St, Pittsburgh, PA 15213.

PEDIATRICS (ISSN 00314005 ). Copyright (C) 1988 by the American Academy of Pediatrics. transplantation centers. ${ }^{4-7}$ Unfortunately, changes in life-style after liver transplantation have been seldom reported ${ }^{8-14}$ and even fewer reports have involved change in the quality of life of children. ${ }^{8,9,14,15}$ Because quality of life is subjective and difficult to measure, we examined objective changes in life-style of children who had undergone liver transplantation and who were observed for as many as 5 years. We evaluated both medical and psychosocial issues affecting these children and their families. Evaluation, indication, selection, and clinical course of these patients have been described elsewhere. ${ }^{3,14-18}$

\section{PATIENT POPULATION AND METHODS}

Between May 9, 1981 and May 9, 1984, 90 pediatric patients received liver transplants at Children's Hospital of Pittsburgh (including one auxiliary transplant and one combined heart-liver transplant). As of May 9, 1986, $65(72.2 \%)$ were still alive. Of the survivors, $27(41.5 \%)$ were boys, 38 $(58.5 \%)$ were girls, $57(87.7 \%)$ were white, and eight $(12.3 \%)$ were black. Age at the time of transplantation ranged from 7 months to $17 \% / 12$ years. Age as of May 9, 1986 ranged from $36 / 12$ to $21^{3 / 12}$ years.

Most patients were reevaluated during routine annual visits to Pittsburgh with detailed interviews of the parents, physical examination, and routine laboratory assessment. When families could not return to Pittsburgh, telephone interviews with both the families and their local physicians were conducted. Information obtained from the interviews concerning hospitalizations and medications was corroborated by review of medical records. All information was gathered after obtaining informed consent from the parents. 
Five intelligence measures were used to test cognitive function: (1) Bailey Scales of Infant Development-Mental Scale; ${ }^{19}$ (2) Merrill-Palmer Scale of Mental Tests; ${ }^{20}$ (3) Stanford-Binet, Form L-M; ${ }^{21}$ (4) Wechsler Preschool and Primary Scale of Intelligence, ${ }^{22}(5)$ Wechsler Intelligence Scale for Children-Revised. ${ }^{23}$ The test appropriate for each patient's chronologic age was administered before transplantation and again at least 1 year after transplantation.

In addition, a subgroup of 24 children with congenital liver disease who received liver transplants between May 1981 and April 1983 and their parents were examined to compare parents' pre- and posttransplantation perceptions of their children in the following areas: (1) gross motor skills; (2) behavior; (3) parent/sibling behavior (ie, were patients being treated in special ways?); and (4) separation/school behavior (ie, were parents fostering separation by encouraging school attendance?) ${ }^{24}$ Parental responses to an open-ended questionnaire were compared to age-appropriate developmental norms and distributed along an ordinal Likert-type continuum with five gradations, 1 to 5 . A congruency score of 5 reported by the parent indicated that the child always exhibited normal standards, whereas a response of 1 indicated that the child never exhibited normal standards. Intermediate scores of 4,3 , and 2 indicated that the child "often," "sometimes," and "seldom," respectively, achieved normal standards. Normal congruency scores ranged from 4.0 to 5.0. Each of the four major areas was evaluated. The developmental examinations that were performed confirmed the accuracy of parental observations in the gross motor category. The Vineland Social Maturity Scale ${ }^{25}$ was administered to parents to pro- vide standards for evaluating the patient's social maturity; a standardized social quotient was compared with the patient's chronologic age. Each of the Vineland's eight subcategories also was analyzed: (1) self-help, general; (2) self-help, eating; (3) self-help, dressing; (4) self-direction; (5) occupation; (6) communication; (7) locomotion; and (8) socialization. One patient who received a transplant between May 1981 and April 1983 was not included for evaluation in the parent's perception and Vineland evaluations because she had a progressive, degenerative CNS disorder. ${ }^{17}$ She is included in all other analyses.

\section{STATISTICAL METHODS}

To compare values of various measures before and after transplantation, techniques for matched pair analyses were used. Both parametric (paired $t$ test) and nonparametric (Wilcoxon matched pair signed-rank) methods were used to compare preand posttransplantation distributions of number of admissions per year, days spent in the hospital per year, number of medications, IQ scores, and behavioral congruency scores. ${ }^{26-28}$ Additionally, the binomial test ${ }^{27}$ was applied to determine whether the variables tended to increase or decrease posttransplantation compared with pretransplantation. For all analyses, statistical significance was defined as $P<.05$.

The number of patients expected to be enuretic was obtained using published norms by age. ${ }^{29}$ For each group, the number of posttransplantation patients was multiplied by the expected proportion of enuretic patients to calculate an expected number. The observed number was compared with the expected number using a $\chi^{2}$ goodness of fit test. ${ }^{26}$

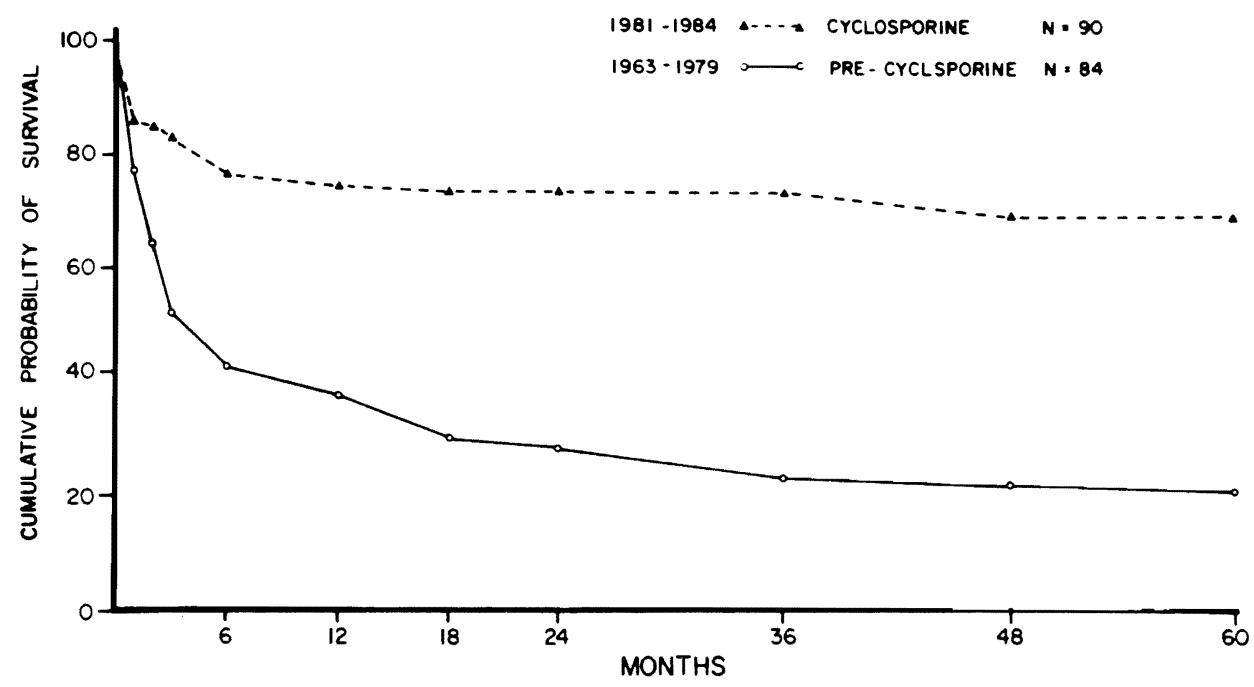

Fig 1. Cumulative probability of survival of children receiving liver transplant treated with cyclosporine $\left(\boldsymbol{\Lambda}_{-}-\mathbf{\Delta}\right) v$ conventional immunosuppressive therapy $(\mathrm{O}-\mathrm{O})$. CutlerEderer method. 


\section{RESULTS}

The mean $( \pm \mathrm{SEM})$ waiting period of 63 of the 65 survivors from the time of evaluation to transplantation was $173.6( \pm 20.7)$ days (range five to 678 days, median 120 days). Length of hospitalization after transplantation surgery for the 65 survivors averaged $58.2( \pm 4.6)$ days (range 16 to 202 days, median 47 days). Of the 65 patients, 45 received one graft, 15 received two grafts, four received three grafts, and one patient received four grafts. These 65 patients represent a survival rate of $70 \%$ (Fig 1 ). Of 25 deaths, 21 occurred in the first 6 months. Of the 25 patients who died, two deaths occurred after 1 year: one patient died secondary to a ruptured portal vein during retransplantation for chronic rejection, and the other patient died with disseminated lymphoma. The 65 survivors were assessed within 60 days of May 9,1986 , with a mean followup time of 37.7 months (range 24 to 60 months).

\section{Admissions}

A total of 51 patients for whom we had information both before and after transplantation averaged $2.43( \pm 0.29)$ admissions per year before transplant surgery and $0.80( \pm 0.15)$ admissions per year after surgery. The difference of $1.63( \pm 0.35)$ is statistically significantly greater than zero. Forty-four (83.6\%) patients had more admissions prior to transplantation than after surgery, whereas only seven $(13.7 \%)$ patients experienced more admissions per year after their surgery than prior to it. Fifteen $(29.4 \%)$ patients had no admissions, and

TABLE 1. Reasons for Hospitalization

\begin{tabular}{lcc}
\hline \multicolumn{1}{c}{ for Admission } & $\begin{array}{c}\text { No. of } \\
\text { Patients }\end{array}$ & $\begin{array}{c}\text { No. of } \\
\text { Admissions }\end{array}$ \\
\hline Viral illness (present or presumed) & 16 & 31 \\
Sclerotherapy & 2 & 16 \\
Rejection & 10 & 14 \\
Migraine & 1 & 10 \\
Hyperkalemia & 4 & 9 \\
Varicella & 8 & 8 \\
Retransplantation & 5 & 6 \\
Seizures & 4 & 6 \\
Dental work & 5 & 5 \\
Hemorrhage & 2 & 5 \\
Otitis media & 2 & 5 \\
Liver biopsy & 3 & 4 \\
Pneumonia & 3 & 3 \\
Pneumocystis carinii pneumonia & 3 & 3 \\
Polyethylene tubes in ears & 2 & 3 \\
Brain abscess & 1 & 3 \\
Tonsilloadenoidectomy & 2 & 2 \\
Biliary obstruction, reconstruction & 2 & 2 \\
Follow-up examination & 2 & 2 \\
All other reasons & $*$ & 21 \\
\hline * The same natient mav have & & \\
\hline
\end{tabular}

* The same patient may have been admitted multiple 1 times for the same reasons. another $15(29.4 \%)$ patients had only one admission after transplantation during the follow-up period.

A total of 49 patients for whom information was available both before and after transplantation spent $30.42( \pm 5.06)$ days per year hospitalized before transplant surgery but only $8.45( \pm 2.26)$ days per year hospitalized after transplant surgery. The difference of $21.97 \mathrm{~d} / \mathrm{yr}( \pm 5.95)$ is statistically significant. Of these 49 patients, $42(85.7 \%)$ spent fewer days hospitalized after transplantation than before it. Reasons for posttransplantation hospitalization are listed in Table 1.

\section{Medications}

The 38 patients for whom information was available both before and after transplantation were administered an average of $4.53( \pm 0.39)$ medications per day before and $3.03( \pm 0.23)$ medications per day after their surgery. The difference of 1.5 $( \pm 0.49)$ is statistically significant $(P<.01)$. Of 62 patients, $33 \%(53.2 \%)$ were taking only cyclosporine and prednisone, whereas another 14 patients $(22.6 \%)$ were taking only one additional medication after transplantation. Twenty-four $(63.2 \%)$ patients took more medications before surgery, whereas nine $(23.7 \%)$ patients took more medications after surgery.

Mean cyclosporine dose was $10.4( \pm 0.81) \mathrm{mg} / \mathrm{kg} /$ d (range 3.4 to $40.9 \mathrm{mg} / \mathrm{kg} / \mathrm{d}$ ), achieving whole blood cyclosporine levels, as performed by high performance liquid chromatography, ${ }^{30}$ of $186.9 \pm$ $13.4 \mathrm{ng} / \mathrm{mL}$ (range 55 to $498 \mathrm{ng} / \mathrm{mL}$ ). The association between the cyclosporine dose and level was statistically significant $(P=.032)$. Mean prednisone dose was $5.2( \pm 0.37) \mathrm{mg} / \mathrm{d}$ (range 0 to $15 \mathrm{mg}$ ) or $0.22( \pm 0.16) \mathrm{mg} / \mathrm{kg} / \mathrm{d}$. Medications other than cyclosporine and prednisone included antihypertensives (25 patients); diuretics (nine patients); anticonvulsants (11 patients); calcium, vitamin D or electrolyte solutions (seven patients); and miscellaneous drugs (ten patients).

\section{Laboratory Results}

Results of liver and renal function tests at the time of follow-up are shown in Table 2. Thirtyeight $(59.4 \%)$ of 64 patients had total bilirubin levels $\leq 1.0 \mathrm{mg} / \mathrm{dL}$ and aspartate aminotransferase and/or alanine aminotransferase levels $\leq 40 \mathrm{IU}$, whereas $53(82.8 \%)$ of 64 patients had bilirubin values $\leq 1.0$ and aspartate aminotransferase and/or alanine aminotransferase values less than twice normal. A statistically significant association existed between BUN and the cyclosporine level $(P$ $=.031)$. No statistically significant association existed between the cyclosporine level and serum 
creatinine $(P=.52)$. Creatinine clearances performed on 31 patients at a mean of $21 / 12$ years after transplantation averaged $99.5 \pm 7.35 \mathrm{~mL} / \mathrm{min} / 1.73$ $\mathrm{m}^{2}$ (range 33-196).

\section{School Level}

Of 60 patients studied after transplantation, one patient had received his graduate equivalency diploma prior to transplantation and two patients were too young to attend school. At the time of follow-up, 29 (50.9\%) of 57 children were in standard and age-appropriate grade levels. Learning disability was diagnosed in two of the 29 children who were placed in their standard track classrooms. A total of $15(26.3 \%)$ patients were 1 year less than their appropriate class level. Hence, 44 of 57 $\mathbf{7} 77.2 \%)$ children were in age-appropriate grade levels or only 1 year behind in school. Seven $(12.3 \%)$ patients were 2 years behind. Five $(8.8 \%)$ patients were in special educational classrooms; four of these five patients had intelligence quotients $\leq 79$ prior to transplantation. At the time of follow-up, all 56 children were attending school or preschool programs on a regular basis. One child had progressive neurologic deterioration after transplantation and is not in school. ${ }^{17}$ Reasons for school delay are shown in Table 3. Days absent from school averaged $13.1 \mathrm{~d} / \mathrm{yr}$, with most children missing school for minor upper respiratory tract illnesses. Only $11 \%$ of days absent were for routine physician visits.

IQ measured in 29 patients prior to transplantation had a mean of $92.2( \pm 3.82)$. At least 1 year after transplantation, these same patients' IQ scores average $93.3( \pm 3.01)$. The difference of 1.10 $( \pm 2.79)$ points is not statistically significant $(P>$ $.10)$. Six patients testing in the defective range ( $\leq 79)$ preoperatively retested in the normal range (80 to 119) after transplant surgery. One patient's test results decreased from 86 to 68 , and three patients' test results decreased from the superior range ( $\geq 120$ ) to the normal range (80 to 119 ).

\section{Behavior}

The results of questionnaires regarding parents' perceptions of their children's gross motor skills, behavior, parent/sibling behavior, and separation/ sthool-behavior in 24 patients with congenital liver disease are summarized in Fig 2. Prior to transplantation most patients exhibited delays in gross motor function. Such delays were most prevalent in preschool children. ${ }^{24}$ The pretransplantation mean congruency score for gross motor function in the 24 patients was $3.43( \pm 0.83)$. One year posttransplantation, the mean congruency score was $4.55( \pm 0.51)$, indicating improved gross motor skills when compared with age-matched children who had not had transplant surgery. Most rapid gains were made among children who were 24 months of age or younger at the time of transplantation.

Overall behavior prior to transplantation was less than that expected for age-matched children who had not had transplant surgery with a mean congruency score of $2.74( \pm 0.94)$. Most parents reported that their children were overly dependent, complaining, and demanding. After transplantation, the mean congruency score was $3.55( \pm 0.99)$, indicating improved overall behavior, although some parents reported more patient defiance and aggression.

Special treatment of the patient by parents and siblings was prevalent prior to transplantation, indicated by a mean congruency score of $2.53( \pm 0.88)$. Parents reported infantilization of the patient, inconsistent discipline, family social isolation, and resentment of the patient by siblings. After transplantation, parent and sibling behavior improved, with a mean congruency score of $3.95( \pm 0.56)$, al-

TABLE 3. Reasons for School Delay $(\mathrm{N}=28)$

\begin{tabular}{lc}
\hline \multicolumn{1}{c}{ Reason } & $\begin{array}{c}\text { No. of } \\
\text { Patients* }\end{array}$ \\
\hline Chronic illness prior to & 11 \\
$\quad$ transplantation & 2 \\
Learning disability & 6 \\
Prolonged hospitalization for & \\
$\quad$ transplantation & 5 \\
Developmental delay & 8 \\
Emotional immaturity & 2 \\
Chronic illness after trans- & \\
plantation & \\
\hline
\end{tabular}

* In this series, six patients had two reasons for school delay.

TABLE 2. Liver and Renal Function Tests at Follow-up

\begin{tabular}{lccccc}
\hline \multicolumn{1}{c}{ Test } & $\begin{array}{c}\text { Normal } \\
\text { Value }\end{array}$ & $\begin{array}{c}\text { No. of } \\
\text { Patients }\end{array}$ & Median & Mean \pm SD & Range \\
\hline Bilirubin (mg/dL) & & & & & \\
$\quad$ Total & $0.3-1.5$ & 65 & 0.6 & $0.67 \pm 0.38$ & $0.1-2.2$ \\
$\quad$ Conjugated & $0.1-0.4$ & 29 & 0.2 & $0.29 \pm 0.25$ & $0-1.0$ \\
$\begin{array}{l}\text { Aspartate aminotransferase } \\
\quad(I U)\end{array}$ & $<34$ & 64 & 36 & $52.1 \pm 60.1$ & $15-463$ \\
$\quad$ & $<37$ & 60 & 24 & $45.8 \pm 69.1$ & $2-468$ \\
$\quad \begin{array}{llll}\text { Alanine aminotransferase (IU) } \\
\gamma \text {-Glutamyl transpeptidase (IU) }\end{array}$ & $<44$ & 37 & 34 & $149.8 \pm 423.3$ & $6-2527$ \\
Creatinine (mg/dL) & $0.2-1.1$ & 61 & 0.7 & $0.84 \pm 0.43$ & $0.2-2.4$ \\
BUN (mg/dL) & $6-18$ & 61 & 22 & $24.0 \pm 14.1$ & $3-104$ \\
\hline
\end{tabular}




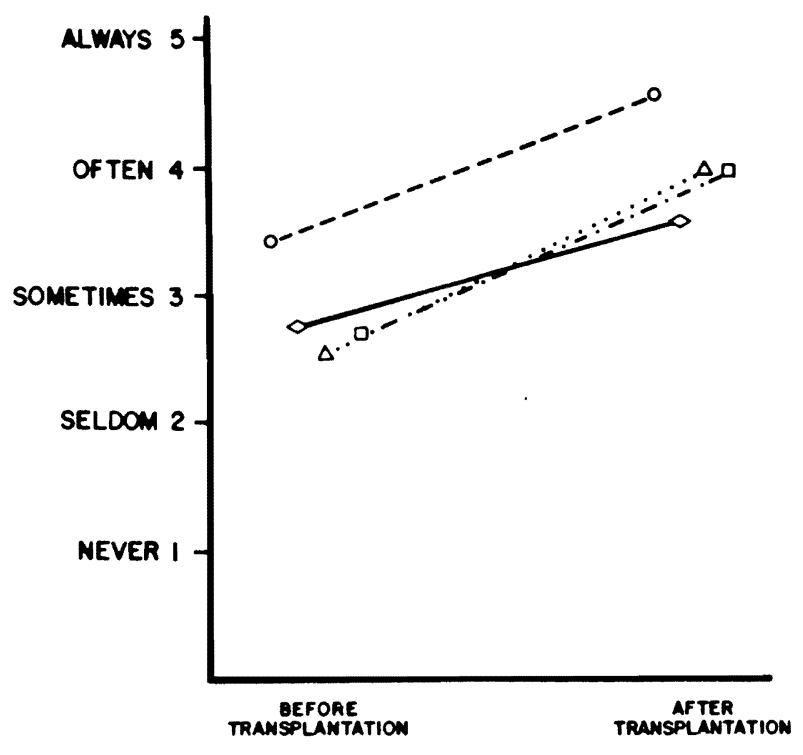

Fig 2. Behavioral congruency scores of 24 patients with congenital liver disease before transplantation and 1 year after transplantation. Score of 5 indicates a patient who always exhibits normal behavior. $\mathrm{O}_{-}-\mathrm{O}$, Gross motor; $\diamond-\diamond$, overall behavior; $\triangle \cdots \cdots \cdot . . \Delta$, parent/sibling behavior; $\square-. .-\square$, school separation behavior.

though parents still tended to foster dependency, and posttransplantation media attention enhanced a continued feeling of "specialness."

School separation behavior was perceived by parents as less than normal before transplantation, with a mean congruency score of $2.70( \pm 1.75)$. Despite available school programs for children before transplantation, patients were viewed as too ill to participate, and some children were kept from school enrollment because of parental anxieties. After transplantation, improvement toward normal behavior was observed, with a mean congruency score of $3.95( \pm 1.58)$. Parents still tended to resist enrolling their children in school because of fear of infection and continued to view the child as vulnerable, at high risk, and less than adequate. Parents still struggled with separation issues.

Statistical analysis of patient congruency scores before and after transplantation in each of the four major areas, using the Wilcoxon matched pair signed-rank method, showed significant improvement $(P<.01)$.

Prior to transplantation, Vineland Social Maturity Scale social quotients were less than age-appropriate levels in all age groups except in the 66 to 72 months of age level (four patients) and the 121 to 132 months of age level (four patients), with delays ranging from 1 to 37 months less than the norm. Greatest delays occurred in children who were older than 3 years of age. At an average age of 37 to 48 months, the children scored 25 months younger than the norm; at an average age of 49 to 60 months, subjects scored 21 months younger than the norm; and the one patient at $181+$ months of age appeared to be 37 months younger than the appropriate age level. Most delays occurred on Vineland subcategories of self-help dressing, selfhelp eating, communication, self-direction, socialization, and locomotion. In the area of socialization, only $46 \%$ of patients passed $\geq 75 \%$ of the Vineland subtest items prior to transplantation. One year after transplantation, all patients passed at least $50 \%$ of the items, and $83 \%$ of the patients passed $\geq 75 \%$ of the subtest questions. One year after transplantation, social quotient scores improved from 17 months (four patients in the 61 to 72 months of age group) to 51 months (the one patient in the $181+$ months of age group). All other age groups were at or beyond age-appropriate levels. Gains were seen in all subcategories except selfdirection, indicating that most patients were not yet able to act responsibly without direct supervision.

\section{Enuresis}

Nineteen of $59(32.2 \%)$ patients studied had nocturnal enuresis at the time of follow-up. The expected rate of enuresis within the age distribution of patients should be $5.43^{29}$ (Fig 3). The difference $(19 v 5.43)$ was statistically significant to an extent greater than would be expected $(P<.005)$. No enuretic patient was taking diuretic medication.

\section{Parental Marital Status Change}

Within the period of follow-up, ten of 59 families experienced changes in parental marital status.

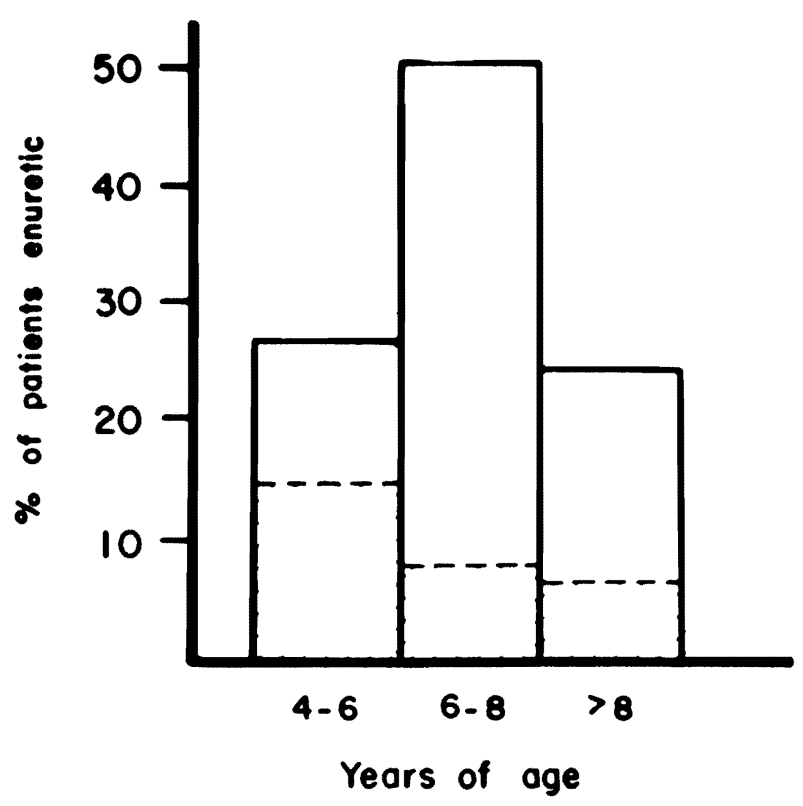

Fig 3. Enuresis in liver transplant recipients compared with population of children with normal liver function. Total bar graph represents percentage of patients with nocturnal enuresis. Shaded area is expected percentage of normal children with nocturnal enuresis. 
Seven couples (11.9\%) divorced, two couples separated, and one single mother married. Three mothers (one separated, two divorced) claimed that the stress of rearing a chronically ill child and of the transplantation significantly contributed to marital discord.

\section{DISCUSSION}

Quality of life is subjective and difficult to measure, especially in children. In an effort to assess the effect of liver transplantation on children, we examined objective changes in life-style after liver transplantation. This represents the only recent such effort of which we are aware and is the largest group of children reported in detail. In 1979 one of the authors summarized observations on the quality of life of 44 patients who received liver transplants and survived at least 1 year in the precyclosporine era. ${ }^{10}$ Twenty-seven patients were 18 years of age or younger; 13 children subsequently died. These patients all received high-dose steroid therapy in addition to azathioprine or cyclophosphamide with or without antilymphocyte globulin. ${ }^{12}$ Most of the children were able to return to school. It was concluded that the quality of life for the group after liver transplantation ranged from "poor to superior."

After the introduction of cyclosporine-steroid immunosuppression, ${ }^{12}$ the 2-year experience of pediatric liver transplantation in 47 patients, with 30 survivors, was reported. ${ }^{14}$ In contrast to those described earlier, ${ }^{10}$ these patients received cyclosporine and low-dose steroids. Although follow-up was brief, it was noted that all children were home, had lost the physical stigmata of chronic disease, had increased energy levels, and were in school. Unfortunately, no other data were available with which to evaluate changes in life-style of pediatric patients after liver transplantation. Our report extends the observations in these and subsequent patients.

Survival after liver transplantation has nearly tripled with the introduction of cyclosporine and low-dose steroid therapy, ${ }^{3,31}$ newer surgical techniques, ${ }^{32}$ and improved medical care. ${ }^{31}$ Survival curves plateau after 6 months to 1 year with fewer late deaths. In precyclosporine series, 18 of $44 \mathrm{pa}$ tients died 1 year after transplantation, and 11 of those patients had significant medical complications at 1 year. ${ }^{10}$ In contrast, only two patients of 67 who survived the first year in the present series died subsequently, at 454 and 1,188 days after initial transplantation. Four patients of the remaining 65 survivors could be considered potentially at risk for retransplantation as of May 1986; one patient subsequently underwent successful combined hepatic and renal transplantation and is at home with normal bepatic and renal function. Because of the plateau of the survival curve, we have every hope that the vast majority of current survivors will continue to do well.

"Doing well" connotes more than just survival, and our patients had significantly fewer hospitalizations after the initial transplantation, as well as significantly fewer days hospitalized. In the precyclosporine era, it was reported that patients spent $39 \%$ of the first year hospitalized, but even in those days survivors beyond 1 year spent an average of only $5 \%$ of their time hospitalized thereafter. ${ }^{10} \mathrm{Sim}$ ilarly, our patients spent an average of slightly more than eight days hospitalized per year (2.3\%) after transplantation. The single greatest cause for admission was viral illness, accounting for nearly one of every five admissions. Most primary caretakers stated that the patients were admitted for observation "to be cautious" and not because the patients were severely ill. In most instances, as primary caretakers became more comfortable managing the patients, fewer admissions occurred for routine viral disease. Most other admissions did occur because of complications related to transplantation such as sclerotherapy for varices secondary to portal vein thrombosis, management of rejection, and infections such as varicella and Pneumocystis carinii pneumonia.

Patients took fewer medications after transplantation than prior to transplantation and most took only cyclosporine and prednisone. Other than immunosuppressive drugs, antihypertensive medication was the most common class of drugs taken. ${ }^{33,34}$ Cyclosporine doses were gradually reduced after transplantation to minimize potential renal injury ${ }^{35}$ and side effects such as hirsutism and gingival hyperplasia. Low prednisone doses achieved with the use of cyclosporine may be, in part, responsible for excellent linear growth achieved by these patients. Of 29 patients, 22 (75.9\%) observed for 2 to $44 / 12$ years after transplantation experienced accelerated or normal growth velocity. ${ }^{18}$ This is in sharp contrast to growth retardation in the precyclosporine era, as exemplified by a girl $8 \% 12$ years of age who was only $95 \mathrm{~cm}$ ( $3 \mathrm{ft} 2 \mathrm{in}$ ) tall. ${ }^{10}$

Abnormal liver function test results were significantly improved after transplantation. Median values for bilirubin and aminotransferases were within the normal range. BUN levels were increased and were associated with cyclosporine dose. Whereas the mean creatinine clearance values were normal, these patients will continue to be observed throughout their lives for cyclosporine-associated nephrotoxicity. ${ }^{36-39}$ Overall, excellent liver and kidney function has relieved these patients from the stigmata of chronic liver disease. No patient has ascites, icterus, or pruritis. Metabolic bone disease 
has healed. Often, children who were nonambulatory prior to transplantation due to rickets or pulmonary hypertrophic osteoarthropathy were able to walk independently within 1 year after their surgery.

More than three quarters of the patients were in age-appropriate school grades or were only 1 year behind. The most common reason for delay was chronic illness prior to transplantation. Because of chronic illness, some children had emotional immaturity that caused a 1 year delay in school. Young adults have completed high school and are either employed or are in college. In addition, it appears that liver transplantation has no significant effect on cognitive function. Two children who suffered cardiac arrests in the perioperative period had significantly lower scores postoperatively, however. Gross motor function, as perceived by parents as well as by independent testing, significantly improved. Although most children had motor delays due to their chronic illness, overall improved health after transplantation promoted accelerated motor skill gains. It was not uncommon for parents to report, "He runs, plays tag, climbs up and down trees, plays Frisbee, ball, and swings on swings. He couldn't do any of that before." ${ }^{24}$

According to parent perception, overall patient behavior, parent and sibling behavior toward the patient, and school separation behavior, improved after transplant surgery. Children were generally more spontaneous and more cooperative. Parents were able to distinguish between true needs and manipulative behavior. Parents tended to view themselves as more relaxed, and they applied more consistency and balance in discipline. Siblings behaved in a more appropriate fashion, although they were still somewhat resentful toward the patient. School enrollment significantly improved after surgery, with most children attending age-appropriate classes. Patients generally interacted well with their peers and participated in such activities as soccer and physical fitness programs with success. Released from the burden of their chronic illness, patients enjoyed activities that they were never able to do before, such as sleeping overnight at a friend's house or going camping. Some patients who did well in school were selected for awards and one patient delivered his high school salutatorian address. Despite overall improvement, parents still did not perceive their child's behavior as entirely normal: behavioral immaturity tended to persist after transplantation; defiance and aggression sometimes were seen; fear of infection and medication side effects remained; and separation anxieties surrounding school enrollment remained an unresolved issue, especially for young school-aged children.
Penn et $\mathrm{al}^{8}$ described their experience with children undorgoing transplantation and found children with biliary atresia had general developmental delays and restricted physical activity prior to transplantation. Patients had limited sibling and peer group interactions and were extremely dependent on their parents. Parents often were excessively indulgent and overly protective. After transplantation, patients with good graft function who had good emotional adjustments prior to transplantation showed striking improvement in motor abilities and showed a sense of pleasure. They interacted freely and more appropriately with peers, siblings, and adults. Other children who were less well adjusted preoperatively, however, developed extreme dependency on the ward environment or severely adverse reactions to hospitalization. The only consistently abnormal behavior noted in our patients was nocturnal enuresis.

Enuresis occurred in our population to a significantly greater extent than expected for the overall population. No patient with enuresis was taking diuretic medication, exhibited a renal concentrating defect, or had diabetes mellitus or a urinary tract infection. Although the cause of enuresis generally is obscure, we speculate that stress, emotional factors, ${ }^{40,41}$ or maturational delay ${ }^{42}$ may be contributory in some patients.

Gold et $\mathrm{al}^{43}$ reported that parents continued to express numerous fears even in the long-term postoperative stage. Concerns centered around fear of rejection, medication side effects, and continued medical expenses. Parents tended to remain overprotective. Mothers sometimes found it difficult to reacquaint themselves with a "well" child; one mother stated, "I feel like I lost my identity." Despite continued family and parental pressures, the divorce rate of nearly $12 \%$ in the parents of our patients was not different from that reported by others in families of chronically ill children. ${ }^{44} \mathrm{Al}$ though this divorce rate is much lower than the overall national average,${ }^{45}$ we did not determine the degree of marital stress that still may be present. Because our follow-up study was relatively brief, these figures may change with time.

In the precyclosporine era, liver transplantation was not offered to children by some transplant surgeons, in part, because of these factors: low survival rates, impact of high-dose steroid and immunosuppressive therapy, continued chronic illness after transplantation, and overall poor quality of life. We have shown, however, that not only have survival rates more than tripled, but also children require small doses of steroids, generally have normal or accelerated linear growth, ${ }^{18}$ are free of the stigmata of chronic disease, spend significantly less time hospitalized after transplant surgery, and ex- 
hibit improved psychosocial behavior. Still, transplantation surgery is costly, both monetarily ${ }^{46}$ and psychosocially. ${ }^{8,43}$ More investigation is required into the emotional impact of chronic illness and transplant surgery on patients and their families. Although this study does not fully address these other issues, we believe that objective changes in life-style are significantly improved after liver transplantation and that liver transplant surgery should be offered as standard therapy for children with end stage liver disease.

\section{REFERENCES}

1. National Institutes of Health Consensus Development Conference Statement: Liver Transplantation-June 20-23, 1983. Hepatology 1984;4(suppl):107S-110S

2. Williams, L, Wood RP, Shaw BW Jr: Role of nursing in the establishment of a liver transplantation progam: Impact on nursing or nursing's impact? Transplant Proc 1987; 19:33673374

3. Zitelli BJ, Malatack JJ, Urbach AH, et al: Pediatric hepatology: a three-year experience with pediatric liver transplantation with cyclosporine and steroids, in Winter PM, Kang YG (eds): Hepatic Transplantation. Philadelphia, Praeger Special Studies, 1986, pp 66-73

4. Cox K: Liver transplants in Australia? Med $J$ Aust $1984 ; 141: 848-850$

5. Best J: Liver transplantation. Med J Aust 1984;141:857-860

6. Sheil AGR: Liver transplantation for Australia. Med J Aust 1984;141:775-777

7. Scharschmidt BF: Human liver transplantation: Analysis of data on 540 patients from four centers. Hepatology $1984 ; 4$ (suppl):95S-101S

8. Penn I, Bunch D, Olenik D, et al: Psychiatric experience with patients receiving renal and hepatic transplants. Semin Psychiatry 1971;3:133-144

9. Dubovsky SL, Metzner JL, Warner RB: Problems with internalization of a transplanted liver. Am $J$ Psychiatry 1979;136:1090-1091

10. Starzl TE, Koep LJ, Schroter GPJ, et al: The quality of life after liver transplantation. Transplant Proc 1979;11:252256

11. MacDougall BRD, Calne RY, McMaster P, et al: Survival and rehabilitation after orthotopic liver transplantation. Lancet 1980;1:1326-1328

12. Starzl TE, Iwatsuki S, Van Thiel DH, et al: Evolution of liver transplantation. Hepatology 1982;2:614-636

13. Tarter RE, Van Thiel DH, Hegedus AM, et al: Neuropsychiatric status after liver transplantation. $J$ Lab Clin Med 1984;103:776-782

14. Gartner JC Jr, Zitelli BJ, Malatack JJ, et al: Orthotopic liver transplantation in children: Two-year experience with 47 patients. Pediatrics 1984;74:140-145

15. Zitelli BJ, Gartner JC Jr, Malatack JJ, et al: Pediatric liver transplantation: Patient evaluation and selection, infectious complications, and life-style after transplantation. Transplant Proc 1987;19:3309-3316

16. Zitelli BJ, Malatack JJ, Gartner JC Jr, et al: Evaluation of the pediatric patient for liver transplantation. Pediatrics 1986;78:559-565

17. Gartner JC Jr, Bergman I, Malatack JJ, et al: Progression of neurovisceral storage disease with supranuclear ophthalmoplegia following orthotopic liver transplantation. Pediatrics 1986;77:104-106

18. Urbach AH, Gartner JC Jr, Malatack JJ, et al: Linear growth following pediatric liver transplantation. Am J Dis Child -1987,141:547-549

19. Bailey N: Manual for the Bailey Scales of Infant Development. New York, Psychological Corp, 1969

20. Manual for the Merrill-Palmer Scale of Mental Tests. Chicago, Stoelting Co, 1984

21. Terman LM, Merrill MA: Manual for the Stanford-Binet Form L-M. Boston, Houghton Mifflin Co, 1973

22. Wechsler D: Manual for the Preschool and Primary Scale of Intelligence. New York, Psychological Corp, 1967

23. Wechsler D: Manual for the Wechsler Intelligence Scale for Children-Revised. New York, Psychological Corp, 1974

24. Miller, JW: Parents' Perceptions of Behavior of Children With Congenital Liver Disease One Year After Liver Transplantation, $\mathrm{PhD}$ dissertation. University of Pittsburgh, Pittsburgh, 1985

25. Doll EA: The Measurement of Social Competence. Chicago, Educational Test Bureau, Educational Publishers, Inc, 1953

26. Snedecor GW, Cochran WG: Statistical Methods, ed 7. Ames, Iowa State University Press, 1980

27. Siegel S: Nonparametric Statistics for the Behavioral Sciences. New York, McGraw Hill Book Co, 1956

28. Lehmann EL: Nonparametrics: Statistical Methods Based on Ranks. Oakland, CA, Holden-Day Inc, 1975

29. Dodge WF, West EF, Bridgforth EB, et al: Nocturnal enuresis in 6 to 10 year old children. Am, $J$ Dis Child 1970; 120:32-35

30. Sawchuk RJ, Cartier LL: Liquid chromatographic determination of cyclosporin A in blood and plasma. Clin Chem 1981;27:1368-1371

31. Starzl TE, Iwatsuki S, Shaw BW Jr, et al: Immunosuppression and nonsurgical factors in the improved results of liver transplantation. Semin Liver Dis 1985;5:334-343

32. Starzl TE, Iwatsuki S, Esquivel CO, et al: Refinements in the surgical technique of liver transplantation. Semin Liver Dis 1985;5:349-356

33. Siegl H, Ruffel B: Effect of cyclosporin on renin-angiotensin-aldosterone system, letter. Lancet 1982;2:1274

34. Joss DV, Barrett AJ, Kendra JR, et al: Hypertension and convulsions in children receiving cyclosporin A, letter. Lancet 1982;1:906

35. Iwatsuki S, Starzl TE, Shaw BW Jr, et al: Long-term use of cyclosporine in liver recipients. Transplantation 1983;36:641-643

36. Klintmalm GBG, Iwatsuki S, Starzl TE: Nephrotoxicity of cyclosporin $\mathrm{A}$ in liver and kidney transplant patients. Lancet 1981;1:470-471

37. Shulman H, Striker G, Deeg HJ, et al: Nephrotoxicity of cyclosporin A after allogenic marrow transplantation. $N$ Engl J Med 1981;305:1392-1395

38. Myers BD, Ross J, Newton L, et al: Cyclosporine-associated chronic nephropathy. $N$ Engl J Med 1984;311:699-705

39. Iwatsuki S, Esquivel CO, Klintmalm GBG, et al: Nephrotoxicity of cyclosporine in liver transplantation. Transplant Proc 1985;17(suppl 1):191-195

40. Oppel WC, Harper PA, Rider RV: Social, psychological, and neurological factors associated with nocturnal enuresis. $P e$ diatrics 1968;42:627-641

41. Spock B: Baby and Child Care. New York, Pocket Books, 1970, pp 350-353, 510-513

42. Meadow R: Childhood enuresis. Br Med $J$ 1970;4:787-789

43. Gold LM, Kirkpatrick BS, Fricker FJ, et al: Psychosocial issues in pediatric organ transplantation: The parents' perspective. Pediatrics 1986;77:738-744

44. Sabbeth BF, Leventhal JM: Marital adjustment to chronic childhood illness: A critique of the literature. Pediatrics 1984;73:762-768

45. National Center for Health Statistics: Provisional statistics. Month Vital Statist Rep 1980;29(6):1-2

46. Luebs HW: Cost considerations. Semin Liver Dis 1985; 5:402-411 